\section{SENSITIVITY RELIEF}

Not everyone welcomes crisp cold mornings; those suffering from dental sensitivity can find this time of year challenging to say the least. Experienced by a wide cross-section of the population, most notably when eating or drinking cold or sweet food, or taking a gasp of cold air, sensitivity is caused by nerves which are stimulated in the dentine layer of teeth exposed by, among other things, tooth wear or periodontal disease.

Sensitivity is often experienced in conjunction with gum irritation. Oral-B know that strong teeth are built on healthy gums. This was the premise behind the launch of their new toothpaste, Oral-B Sensitivity \& Gum Calm. It contains stabilised stannous fluoride which acts by blocking the dentinal tubules and thus preventing the stimuli causing the painful nerve impulses. Used regularly it will continue to block the tubules thereby providing ongoing sensitivity relief.

The inclusion of stabilised stannous fluoride also gives Oral-B's Sensitivity \& Gum Calm toothpaste an antimicrobial action, which fights plaque and consequently gum problems. The stabilised stannous fluoride will inhibit antimicrobial growth as well as reducing the ability of bacteria to 'stick' to tooth and gum surfaces.

All toothpastes are not the same. Whilst the inclusion of fluoride is a given, to afford maximum protection, a formulation must contain other proven ingredients that work in harmony together to promote good oral health. Oral-B Sensitivity \& Gum Calm is formulated to strengthen teeth and soothe what they are built on, gums!

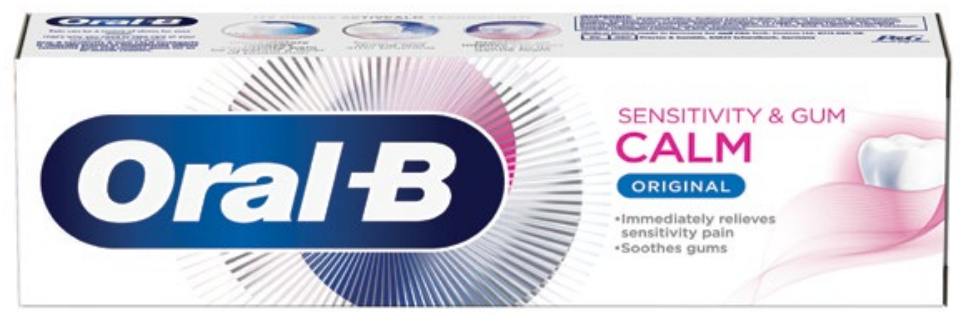

\title{
BETTER BRUSHING FOR WELLBEING
}

More of your patients will now be interested in wellbeing, so they must know how to brush properly, to not just avoid dental disease but also reduce the risk of other serious conditions.

When they have a tool that they enjoy using, the level of daily cleaning will improve. Recommend they try the Hydrosonic Pro electric toothbrush from oral healthcare specialist, Curaprox.

The Hydrosonic Pro will keep them motivated. It features CURACURVE ergonomics, so it's comfortable to hold and delivers up to 42,000 motions a minute, for a deep but gentle clean.

Support your patients to achieve optimal oral health every day with Curaprox. For more information call 01480862084 , email info@curaprox.co.uk or visit www.curaprox. co.uk.

\section{CLEAN IN-BETWEEN}

Crisp packets, business cards, penknives

- these are just some of the weird and wonderful things that patients have admitted using to remove debris from between their teeth.

But as well as risking infection and harm to gingiva, cleaning interdentally with such items can damage the teeth and cause abrasion-based wear on the enamel.

Tooth wear can cause a host of problems, both aesthetic and functional. Using a specially designed tool to clean between the teeth will remove the optimum amount of debris gently, yet efficiently.

Tandex interdental brushes, the FLEXI and the PROXI, come in a variety of sizes so are suitable for all patients. Easy to use and effective, they can fit into all the small spaces. In a variety of bold colours, they look good too. Used alongside Tandex GEL, which contains $0.2 \%$ sodium fluoride, your patients will get a thorough, non-abrasive clean.

The FLEXI and PROXI are part of Tandex's range of high-quality oral health products, including toothbrushes and mouthwashes. Recommend Tandex to your patients - they'll never need reach for a credit card to clean their teeth again!

For more information on Tandex's range of products, visit www.tandex.dk.

UPGRADED INFECTION CONTROL

OPTIM 1 wipes are a fast and effective one-step cleaner and disinfectant, with a 30-second contact time for COVID-19 and a one-minute contact time for other viruses and bacteria, in accordance with EN 16615.

You can use them on a range of surfaces including the hard, non-porous materials found in every practice. They have been tested and passed for all common dental chairs.

The OPTIM range is proven to work against viruses even tougher than Coronavirus - find out more at: https:// bit.ly/33R3QE0. For a FREE sample emailinfo.uk@coltene.com. For more on COLTENE, visit www.coltene.com, or call 08002545115. 